\title{
THE LEVY INSTITUTE MEASURE OF ECONOMIC WELL-BEING UNITED STATES, 1989-2001
}

\author{
Edward N. Wolff \\ New York University, Department of Economics \\ and \\ The Levy Economics Institute of Bard College \\ and \\ Ajit Zacharias \\ The Levy Economics Institute of Bard College
}

\section{INTRODUCTION}

Economic well-being refers to the household's command over, and access to, the goods and services produced in a modern market economy during a given period of time. The magnitude of the command or access that can be exercised by the household is approximated by an income measure, since household income should, in principle, reflect the resources available to the household for facilitating current consumption or acquiring assets. Traditionally, household money income is used as a measure that reflects such command.

Our aim in this paper is to propose a new measure of economic well-being. Gross money income (MI), the most widely used measure of economic well-being in the United States and several advanced capitalist countries, has been criticized on several grounds. The landmark report by the Canberra Group, a group of international experts on household income statistics, recommended, among other things, that estimates of in-kind social benefits need to be added and tax burden subtracted from money income to arrive at a better measure of household economic well-being [Canberra Group, 2001]. In a welcome and significant shift, the U.S. Census Bureau placed its "experimental measures of income" on par with gross money income (MI) in its annual reports [DeNavas-Walt et al., 2003]. The Bureau's most comprehensive measure, which we refer to as extended income (EI), is a better approximation of a household's command over commodities than MI, which is the most widely used official measure. EI is an after-tax measure of income. It expands the definitions of income from work and income from wealth. Furthermore, it has a better accounting of the government's role in household economic well-being.

The EI and MI measures seek to estimate the command over commodities. Although commodities are of critical importance, they form only a portion of the entire

Edward N. Wolff: Department of Economics, New York University-, 695 Park Avenue, New York, New York 10021. E-mail: Howard.Chernick@Hunter.cuny.edu. 
set of goods and services available to households. The state plays a crucial role in the direct provisioning of the "necessaries and conveniences of life" (to use Adam Smith's famous expression), such as public education and highways ("public consumption"). Nonmarket household work, such as childcare, cooking, and cleaning, also provides the necessaries and conveniences of life ("household production").

The Levy Institute Measure of Economic Well-Being (LIMEW) is a more comprehensive measure than the two official measures. We include estimates of public consumption and household production in our measure, components that are excluded in most available measures of economic well-being. We also include estimates of long-run benefits from the ownership of wealth (other than homes) in the form of an imputed lifetime annuity, a procedure that, in our view, is superior to considering only current income from assets. Finally, we include an estimate of consumption taxes, in addition to income, payroll and property taxes, to arrive at a fuller picture of the household tax burden.

The argument that conventional measures are inadequate as a measure of economic well-being because of their omission of elements such as household production or their treatment of income from financial assets is hardly novel. In fact, there exists a substantial body of research, including the pioneering work being done at the Census Bureau itself, which has attempted to include, in addition to money income, one or the other elements mentioned to arrive at a more complete measure of income. What is novel about the LIMEW is that while previous research has typically attempted to include the effect of one element or the other in isolation, we integrate all of them simultaneously, into a comprehensive measure.

There are three key motivations behind constructing the LIMEW. First, trends in well-being can be sensitive to how we choose to measure well-being. A broader measure of well-being might be better guide to actual trends in the economic determinants of the standard of living. While adding new components such as public consumption and household production to conventional measures of well-being is bound to raise the measured level of household well-being, it is also important to know: by how much? This might serve as a starting point to a quantitative assessment of the importance of non-market provisioning in sustaining living standards.

Another motivation behind developing the LIMEW is to study disparities among households in key demographic groups. By focusing only on money income, we might end up with a partial picture of the advantage or disadvantage faced by particular groups in one or more dimensions of well-being. For example, costs incurred by the government in paying public pensions to the elderly (e.g., Social Security payments) are included in their money income while the costs incurred by the government in the education of the young is not counted as a part of their economic well-being. Admittedly, there are problems in quantifying the latter but it is hard to believe that the best estimate of it is zero. Finally, the LIMEW is also motivated by the consideration that economic inequality is broader than inequality in earnings, the main focus of most academic studies and the main driving force behind the changes in the inequality of money income. As one would expect, household production and public consumption are distributed much more equally than earnings among households. On the other hand, inequality in the ownership of assets is a crucial determining factor in overall 
inequality. As is well known, the inequality in wealth is generally much higher than that in income or earnings. Including an estimate of the long-run benefits from wealth in the measure of well-being will therefore boost measured inequality. In sum, our understanding of the extent and nature of group inequalities and overall inequality depends on the measure of well-being.

We begin by describing briefly the methodology for the LIMEW. The sources of data and methods used are described in the appendix. In the subsequent section, we provide estimates that demonstrate that the economic fortunes of the average household over the 1990s appear to have followed substantially different trends depending on the yardstick of well-being used. The next section compares results based on the LIMEW and conventional measures for households in some key demographic groups. We discuss, in some detail, how the different components of the measures (income from wealth, government transfers etc.) contribute toward widening or narrowing disparities among groups. In the following section, we discuss the overall distribution of economic well-being. We compare our findings regarding inequality based on the LIMEW with those based on the official measures, highlighting the role of the individual components in shaping the differences in findings. Some policy implications are discussed in the concluding section.

\section{COMPONENTS OF THE LIMEW}

The LIMEW is constructed as the sum of the following components (see Table 1): base income; income from wealth; net government expenditures (transfers and public consumption, net of taxes); and household production. ${ }^{1}$

Base income is simply gross money income less the sum of property income (interest, dividends, and rents) and government cash transfers (e.g., Social Security benefits) plus employer contributions for health insurance. Earnings make up the overwhelming portion of base income. Adding employer contributions to health insurance, by far the most important type of employer-provided in-kind compensation for work in the United States, expands the definition of income from work. The remainder of base income consists of pensions and other small items, such as interpersonal transfers and workers' compensation paid by the private sector.

The second item added to base money income is imputed income from wealth. In the official gross money income measure, property-type income consists of the actual receipts of interest, dividends, and rent. From our perspective, the actual, annual property income is an incomplete measure of the economic well-being derived from the ownership of assets. Real assets, such as houses, typically last for several years and yield services to their owners, thereby freeing up resources otherwise spent on housing. Financial assets, can, under normal conditions, be a source of economic security in addition to property-type income.

Our approach to the valuation of income from wealth is different from the methods suggested in the literature (e.g., Weisbrod and Hansen [1968]) in two significant ways. First, we distinguish between home and nonhome wealth. Housing is a universal need and home ownership frees the owner from the obligation of paying rent, leaving an equivalent amount of resources for consumption and asset accumulation. Hence, 
benefits from owner-occupied housing are reckoned in terms of the replacement cost of the services derived from it (i.e., a rental equivalent). ${ }^{2}$ Second, we estimate the benefits from nonhome wealth using a variant of the standard lifetime annuity method. ${ }^{3}$ We calculate an annuity based on a given amount of wealth, an interest rate, and life expectancy. The annuity is the same for the remaining life of the wealth holder and the terminal wealth is zero. (In the case of households with multiple adults, we use the maximum of the life expectancy of the head of household and spouse in the annuity formula.) We modify the standard procedure by accounting for differences in portfolio composition across households. Instead of using a single interest rate for all assets, we use a weighted average of asset-specific and historic real rates of return, ${ }^{4}$ where the weights are the proportions of the different assets in a household's total wealth.

TABLE 1

A Comparison of the LIMEW and Extended Income (EI)

\begin{tabular}{|c|c|c|c|}
\hline \multicolumn{2}{|r|}{ LIMEW } & & EI \\
\hline \multicolumn{2}{|c|}{ Money income (MI) } & \multicolumn{2}{|c|}{ Money income (MI) } \\
\hline Less: & $\begin{array}{l}\text { Property income and Government cash } \\
\text { transfers }\end{array}$ & Less: & $\begin{array}{l}\text { Property income and Government cash } \\
\text { transfers }\end{array}$ \\
\hline Plus: & $\begin{array}{l}\text { In-kind compensation from work } \\
\text { Employer contributions for health } \\
\text { insurance }\end{array}$ & Plus: & $\begin{array}{l}\text { In-kind compensation from work } \\
\text { Employer contributions for health } \\
\text { insurance }\end{array}$ \\
\hline
\end{tabular}

Equals: Base income

Equals: Base income

Plus: Income from wealth Annuity from nonhome wealth

Plus: Income from wealth

Imputed rent on owner-occupied housing Property income and realized capital gains (losses) Imputed return on home equity
Less: Taxes
Income taxes ${ }^{1}$
Payroll taxes ${ }^{1}$
Property taxes ${ }^{1}$
Consumption taxes
Less: Taxes
Income taxes
Payroll taxes
Property taxes

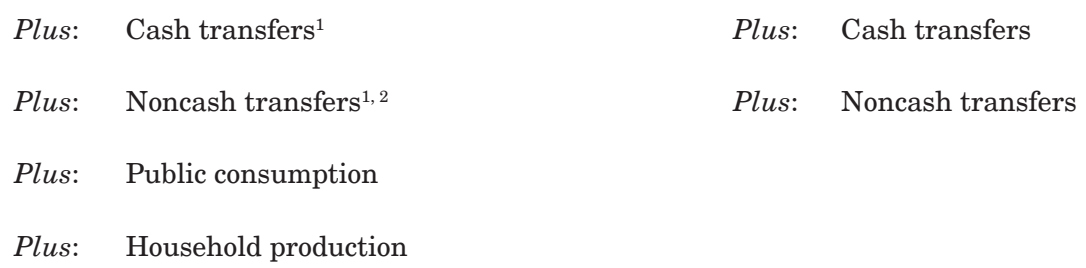

Equals: LIMEW

Equals: EI

Note: (1) The amounts estimated by the Census Bureau and used in EI are modified to make the aggregates consistent with the NIPA estimates. (2) The government-cost approach is used: the Census Bureau uses the fungible value method for valuing Medicare and Medicaid in EI. The main difference between the two methods is that, while the fungible value method assigns an income value for a benefit according to the recipient's level of income, the government-cost approach assigns an income value for a benefit irrespective of the recipient's income. 
The third item that we add to base money income is net government expendituresthe difference between government expenditures incurred on behalf of households and taxes paid by households. Our approach to determine expenditures and taxes may be called the social accounting approach [Hicks, 1946; Lakin, 2002, 43-46].

Government expenditures included in the LIMEW consist of cash transfers, noncash transfers, and public consumption. These expenditures, in general, are derived from the National Income and Product Accounts [NIPA Tables 3.12 and 3.15.5]. The social accounting approach to government expenditures yields the generally accepted conclusion in the case of government cash transfers: they are to be considered entirely as part of money incomes of the recipients. Our approach to noncash transfers is that they must be distributed among recipients on the basis of the appropriate average cost incurred by the government. ${ }^{5}$ In contrast, the Census Bureau includes the "fungible value" of the medical benefits in EI. The fungible value method is based on the theoretical argument that the income-value for the recipient from a given noncash transfer is, on the average, less than the average cost incurred by the government in providing that benefit (see, for example, Canberra Group, [2001, 24,65]). In practice, this involves estimating how much the household could have paid for the medical benefit, after meeting its expenditures on some basic items (such as food, clothing etc.), with the maximum payment for the medical benefit set equal to the average cost incurred by the government.

The alternative is not pursued by us primarily because of its important implication that households with incomes below the minimum threshold and participating in the program are presumed to receive no benefit from a product that they actually consume. This is inconsistent with our goal of measuring the household's access or command over products. Further, unlike the social accounting approach, the alternative method would not, by definition, yield the actual total government expenditure when aggregated across recipients. Such a feature is incompatible with our goal of estimating net government expenditures using a consistent methodology.

The other type of government expenditure that we include in our measure of wellbeing is some public expenditures ("public consumption"). We begin with a detailed functional classification of government expenditures on direct provisioning and exclude certain functions entirely because they fail to satisfy the general criterion. Most such functions form part of general social overhead and their major effect is to keep the ship of state afloat (e.g., national defense). Expenditures under other functional categories also may not meet the general criterion fully because part of such expenditures can be considered as being incurred on behalf of the business sector (e.g., transportation). The household sector's share in such expenditures can be approximated on the basis of information regarding its utilization or consumption of products provided via the expenditures. Finally, expenditures under certain functional categories are considered as incurred completely on behalf of the household sector (e.g., health).

In the second stage, the allocated expenditures for each functional category-public consumption-are distributed among the households. The distribution procedures followed by us build on the earlier studies employing the government cost approach (e.g., Ruggles and O'Higgins [1981]) in that some expenditures are distributed, in 
the same way as the split was made between the household and other sectors, on the basis of estimated patterns of utilization or consumption and some expenditures are distributed equally among the relevant population.

The final step in constructing net government expenditures is concerned with taxes. Our objective is to determine the distribution of actual tax payments by households in different income and demographic groups in an accounting sense rather than incidence in a theoretical sense. We align the aggregate taxes in the ADS (imputed by the Census Bureau) with their NIPA counterparts, as for expenditures. The bulk of the taxes paid by households falls in this group-federal and state personal income taxes, property taxes on owner-occupied housing, and payroll taxes (employee portion). Our estimated total tax burden on households also includes state consumption taxes, which were not aligned with a NIPA counterpart. Taxes on corporate profits, on business-owned property, and on other businesses, as well as nontaxes, were not allocated to the household sector because we assumed that they were paid out of business sector incomes.

The final item that we add to base money income is the imputed value of household production. Three broad categories of unpaid activities are usually included in the definition of household production: (1) core production activities, such as cooking and cleaning; (2) distribution activities, such as shopping for groceries and for clothing; and (3) childcare activities, such as caring for babies and reading to children. These activities are considered as "production", since they can be assigned, generally, to third parties apart from the person who performs them, although third parties are not always a substitute of the person, especially for the third activity. ${ }^{6}$

Our strategy for imputing the value of household production is to value the amount of time spent by individuals on household production using the replacement cost based on average earnings of domestic servants or household employees [Kuznets et al, 1941, 432-433; Landefeld and McCulla, 2000]. Research suggests that there are significant differences among households in the quality and composition of the "outputs" of household production as well as the efficiency of housework [National Research Council, 2005, Ch. 3]. The differentials are correlated with household-level characteristics (such as wealth) and characteristics of household members (such as the influence of parental education on childrearing practices, e.g., Yeung and Stafford [2003]). Therefore, we modify the replacement-cost procedure and apply to the average replacement cost a discount or premium that depends on how the individual (whose time is being valued) ranks in terms of a performance index. Ideally, the performance index should account for all the factors relevant in determining differentials in household production and the weights of the factors should be derived from a full-fledged multivariate analysis. Given the absence of such research findings we incorporated three key factors that affect efficiency and quality differentials—household income, educational attainment, and time availability-with equal weights attached to each of them.

\section{LEVEL AND COMPOSITION OF WELL-BEING}

The picture regarding economic well-being is substantially different between the LIMEW and the official measures. By construction, MI and EI have average values 
less than the LIMEW. The median values of the official measures amount to approximately 60 percent of the LIMEW in 2001 and approximately 65 percent in 1989 (see Table 2). The three measures also show different rates of change. The most favorable rate of increase is given by the LIMEW (12.2 percent), followed by EI ( 6.4 percent) and MI (2.1 percent).

TABLE 2

Economic Well-Being by Measure of Well-Being

\begin{tabular}{|c|c|c|c|c|}
\hline & \multicolumn{4}{|c|}{ Median values (dollar amounts in $2001 \$$ ) } \\
\hline & 1989 & 1995 & 2000 & 2001 \\
\hline \multicolumn{5}{|l|}{ Levy measures } \\
\hline LIMEW & 64,150 & 64,645 & 70,841 & 72,004 \\
\hline $\mathrm{PFI}^{1}$ & 48,168 & 49,860 & 53,607 & 54,629 \\
\hline LIMEW-C ${ }^{2}$ & 40,583 & 41,548 & 44,631 & 45,392 \\
\hline \multicolumn{5}{|l|}{ Official measures } \\
\hline Money income (MI) & 41,310 & 39,510 & 43,195 & 42,198 \\
\hline \multirow[t]{3}{*}{ Extended income (EI) } & 40,623 & 40,811 & 43,835 & 43,206 \\
\hline & \multicolumn{4}{|c|}{ Percentage change } \\
\hline & 1989-95 & 1995-00 & $2000-01$ & $1989-2001$ \\
\hline \multicolumn{5}{|l|}{ Levy measures } \\
\hline LIMEW & 0.8 & 9.6 & 1.6 & 12.2 \\
\hline PFI & 3.5 & 7.5 & 1.9 & 13.4 \\
\hline LIMEW-C & 2.4 & 7.4 & 1.7 & 11.9 \\
\hline \multicolumn{5}{|l|}{ Official measures } \\
\hline Money income (MI) & -4.4 & 9.3 & -2.3 & 2.1 \\
\hline Extended income (EI) & 0.5 & 7.4 & -1.4 & 6.4 \\
\hline
\end{tabular}

1. Post-Fiscal Income (PFI) = LIMEW less the value of household production.

2. LIMEW-C = LIMEW less the value of household production and public consumption.

Table 2 also shows two measures that are related to the LIMEW. As noted in the introduction, EI and MI are measures that seek to estimate the magnitude of the command over commodities. If we exclude public consumption and household production from the LIMEW, we arrive at a similar measure: LIMEW-C. EI is particularly suited to be compared with LIMEW-C because both estimates are post-tax, post-transfer measures of economic well-being. The addition of public consumption to LIMEW-C results in a "post-fiscal income" (PFI) measure that reflects the effect of net government expenditures, which includes public consumption in addition to transfer payments net of taxes. Similar to the LIMEW, these measures also show much higher percentage increases between 1989 and 2001, as compared to the official measures.

The differences in the picture of well-being that is conveyed by the various measures are due to their individual components (e.g., public provisioning is included in the LIMEW, but not in the official measures) and the manner in which the components are included in the measure (e.g., income from nonhome wealth is included as a lifetime annuity in the LIMEW, but as the sum of property income and realized net capital gains in EI). As it turns out, the differences in the level of mean values across the measures are similar to the differences in the median values. As shown in Table 3 , the rates of change in the mean values of the measures between 1989 and 2001 
are also substantially different: MI and EI grew at comparable rates (14.2 and 12.3 percent respectively) while the LIMEW grew much faster at 22.8 percent.

TABLE 3

Change in economic well-being, 1989 to 2001

(All dollar amounts are mean values in 2001 dollars)

\begin{tabular}{|c|c|c|c|c|c|c|}
\hline & \multicolumn{3}{|c|}{ LIMEW } & \multicolumn{3}{|c|}{ Extended income (EI) } \\
\hline & 1989 & 2001 & $\begin{array}{c}\text { Contribution } \\
\text { to change } \\
\text { (in percent) }\end{array}$ & 1989 & 2001 & $\begin{array}{l}\text { Contribution } \\
\text { to change } \\
\text { (in percent) }\end{array}$ \\
\hline Base income & 45,322 & 53,179 & 10.0 & 45,322 & 53,179 & 16.6 \\
\hline Income from wealth & 14,396 & 22,222 & 9.9 & 8,678 & 8,571 & -0.2 \\
\hline Net gov. expenditure & 1,064 & 869 & -0.2 & $-6,560$ & $-8,488$ & -4.1 \\
\hline Transfers & 7,108 & 9,157 & 2.6 & 5,408 & 6,593 & 2.5 \\
\hline Public consumption & 7,416 & 8,697 & 1.6 & & & \\
\hline Taxes & $-13,461$ & $-16,985$ & -4.5 & $-11,968$ & $-15,081$ & -6.6 \\
\hline Household production & 18,002 & 20,456 & 3.1 & & & \\
\hline Total & 78,783 & 96,726 & 22.8 & 47,440 & 53,262 & 12.3 \\
\hline Addendum: & & & & & & \\
\hline Money income & 50,981 & 58,213 & 14.2 & & & \\
\hline
\end{tabular}

In an accounting sense the percentage change in an income measure can be expressed as the sum of the contributions by the individual components. As shown in Table 3, base income is the only identical component in concept and amount for both the LIMEW and EI. In the LIMEW, base income accounted for 10 percentage points of the total change (22.8 percentage points). Base income's contribution to the change in EI exceeded the total change in EI (12.3 percentage points), but it was offset by the negative contributions from income from wealth and net government expenditures (transfers, net of taxes). While the contribution of net government expenditures to the change was negative in both measures, the effect was smaller in the LIMEW owing to the inclusion of public consumption. In contrast to EI, the component reflecting income from wealth in the LIMEW showed a strong positive contribution to the change in economic well-being that was almost as large as the contribution from base income. This reflects primarily the striking growth in the mean amount of nonhome wealth between the two years (not shown in table 3): Nonhome wealth in 2001 was higher than its 1989 level by 60 percent. Finally, household production, which has no counterpart in EI, also contributed positively to the change in the LIMEW.

The composition of the LIMEW for various years is shown in Figure 1. The most notable change is in the income from wealth component: after fluctuating in the range of 18 to 19 percent in 1989 and 1995, it surged to 24.8 percent in 2000 before retreating to 23 percent in 2001 . The fluctuations largely reflect movements in stock prices, particularly the bull market of the late 1990s and the stock market collapse in 2001. Net government expenditures peaked at 3.4 percent in 1995 and bottomed at -0.2 percent in 2000 . Although positive in 2001 , it was still below its 1989 level, as a percentage of the LIMEW and in absolute terms (see Table 3), because of a higher tax burden. The share of household production fell from 22.9 percent in 1989 to 20.7 percent in 2000, before rising to 21.1 percent in 2001 . 
FIGURE 1

Composition of the LIMEW, 1989 to 2001 (percent)

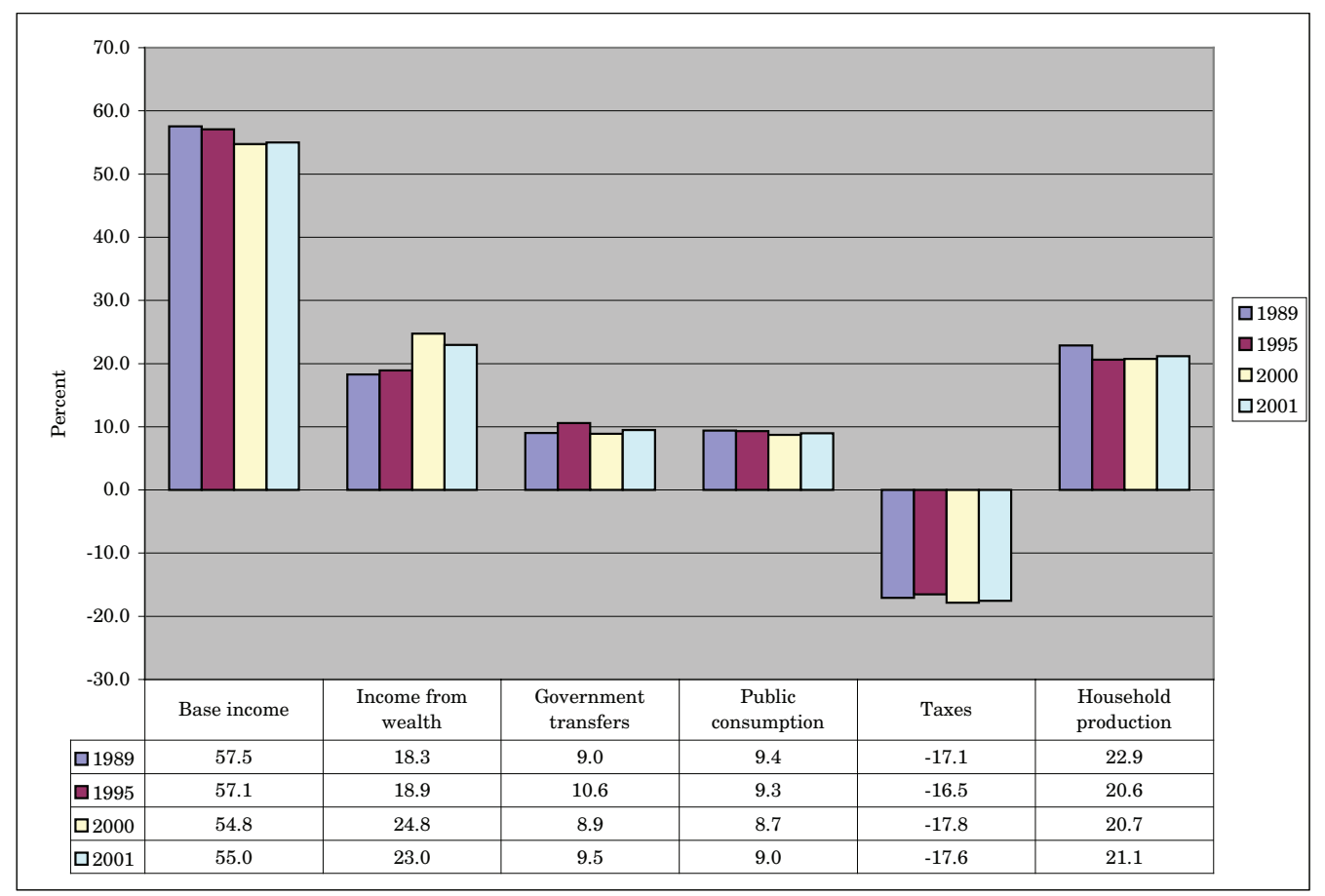

TABLE 4

Composition of LIMEW by Quintile, 1989 and 2001

\begin{tabular}{|c|c|c|c|c|c|c|}
\hline Quintiles & $\begin{array}{l}\text { Mean LIMEW } \\
\text { (in 2001\$) }\end{array}$ & Total & $\begin{array}{c}\text { Base } \\
\text { income }\end{array}$ & $\begin{array}{c}\text { Income } \\
\text { from wealth }\end{array}$ & $\begin{array}{l}\text { Net government } \\
\text { expenditures }\end{array}$ & $\begin{array}{l}\text { Household } \\
\text { production }\end{array}$ \\
\hline & \multicolumn{6}{|c|}{1989} \\
\hline Lowest & 24,054 & 100 & 52.4 & 6.9 & 19.7 & 20.9 \\
\hline Second & 44,534 & 100 & 56.1 & 7.6 & 13.8 & 22.5 \\
\hline Third & 64,223 & 100 & 59.5 & 8.2 & 8.2 & 24.2 \\
\hline Fourth & 89,062 & 100 & 63.4 & 10.1 & 1.7 & 24.9 \\
\hline \multirow[t]{2}{*}{ Highest } & 172,038 & 100 & 54.9 & 30.6 & -7.1 & 21.7 \\
\hline & \multicolumn{6}{|c|}{2001} \\
\hline Lowest & 25,702 & 100 & 63.2 & 7.0 & 8.8 & 21.0 \\
\hline Second & 49,404 & 100 & 56.6 & 7.2 & 14.4 & 21.9 \\
\hline Third & 72,302 & 100 & 58.1 & 8.8 & 9.8 & 23.3 \\
\hline Fourth & 102,740 & 100 & 59.7 & 11.2 & 4.2 & 24.9 \\
\hline Highest & 233,479 & 100 & 50.7 & 37.7 & -7.0 & 18.7 \\
\hline
\end{tabular}

It is also interesting to examine how the composition of the LIMEW has changed for households in different parts of the distribution because the relative importance of individual components can vary across the distribution (Table 4). The most dramatic change appeared to have taken place at the bottom and top of the LIMEW distribution. At the bottom quintile, the share of net government expenditures declined notably, 
from 19.7 percent of the LIMEW in 1989 to 8.8 percent in 2001. This decline was matched by an increase in the share of base income, from 52.4 percent to 63.2 percent over the same period. At the top quintile, there was a sizeable increase in the share of income from wealth, as it rose from 30.6 percent in 1989 to 37.7 percent in 2001 . Declines in the relative importance of base income (from 54.9 percent to 50.7 percent) and household production (from 21.7 percent to 18.7 percent) accompanied the sharp growth in income from wealth at the top. Thus, it appears that the transformation in the structure of well-being over the 1990s has played out differently for those at the bottom and the top. For those at the bottom, the transformation has meant a greater reliance on base income (mainly consisting of labor income) and smaller reliance on net government expenditures. On the other hand, for those at the top, income from wealth has become significantly more important than base income and household production.

\section{DISPARITIES IN ECONOMIC WELL-BEING}

The extent of disparities among households grouped according to salient social and economic characteristics and how these disparities change over time depend on the yardstick used for measuring well-being. In this section, we will discuss groupings based on the following characteristics of the householder ${ }^{7}$ : race/ethnicity, marital status and sex, and age. Our indicator of disparity between the subgroups within a particular grouping (e.g., nonwhite versus whites in the grouping based on race) is relative economic well-being, as expressed by the ratio of mean values (e.g., the ratio of nonwhite LIMEW to white LIMEW). ${ }^{8}$ Because the constituent components of the LIMEW and official measures differ in important ways, we also break down the absolute gap (measured in dollars) in well-being between subgroups into components. This is helpful in highlighting whether the sources of disparities differ by well-being measure (e.g., how large is the role of income from wealth in accounting for the wellbeing gap between whites and nonwhites in the LIMEW as compared to the EI?).

Let us first consider the trends in racial disparities (Figure 2A). Each bar in the figure represents a ratio of mean values using the LIMEW, EI, and MI. Nonwhites are at a similar disadvantage in 2000 according to LIMEW or EI: their well-being is only 77 percent of that of whites ${ }^{9}$, while MI shows a still lower relative well-being at 74 percent. However, the trend in disparity between 1989 and 2000 is notably different according to the two measures. The LIMEW indicates a worsening of the relative wellbeing of nonwhites while the EI and MI suggests slight improvement (the nonwhite mean LIMEW was 83 percent of the whites' in 1989, as compared to 75 percent for EI and 72 percent for MI). A major reason behind the worsening of the relative LIMEW of nonwhites is the growing wealth gap: their income from wealth was nearly half of whites' in 1989 (46 percent), but it dropped sharply to a level of only 28 percent in 2000 , thus offsetting the trend toward greater parity in the other components.

The absolute amounts by which the components of the LIMEW and EI differ between whites and nonwhites show the distinct role played by the racial wealth gap (Figure 2B). In 2001, the average LIMEW for nonwhite households was roughly $\$ 24,000$ less than that for white households while the nonwhite mean EI was lower by about $\$ 13,000$ (numbers associated with bars labeled "Total" in Figure 2B). The 
FIGURE 2A

Racial Disparity, 1989 and 2001

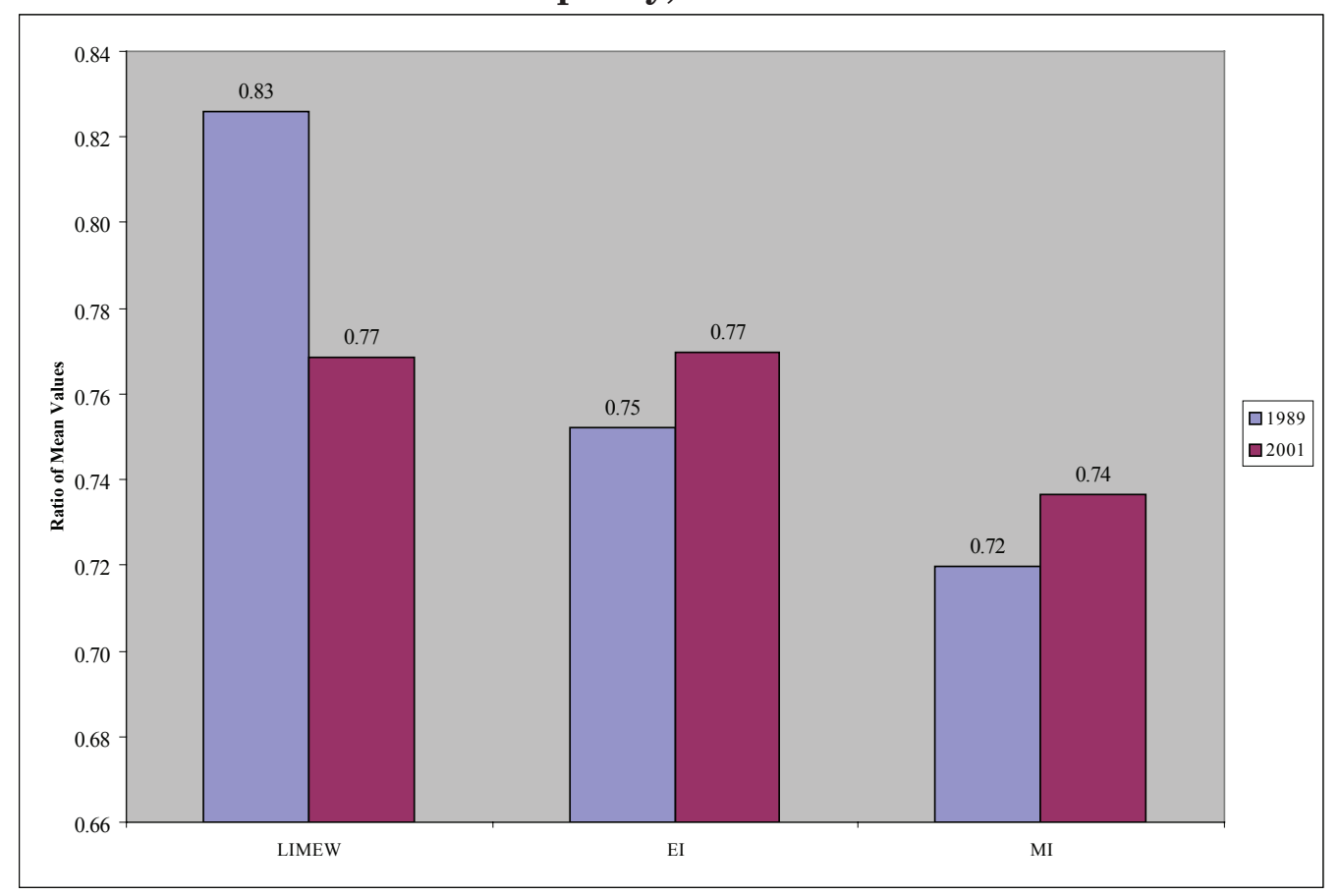

FIGURE 2B

Racial Disparity in Components, 2001

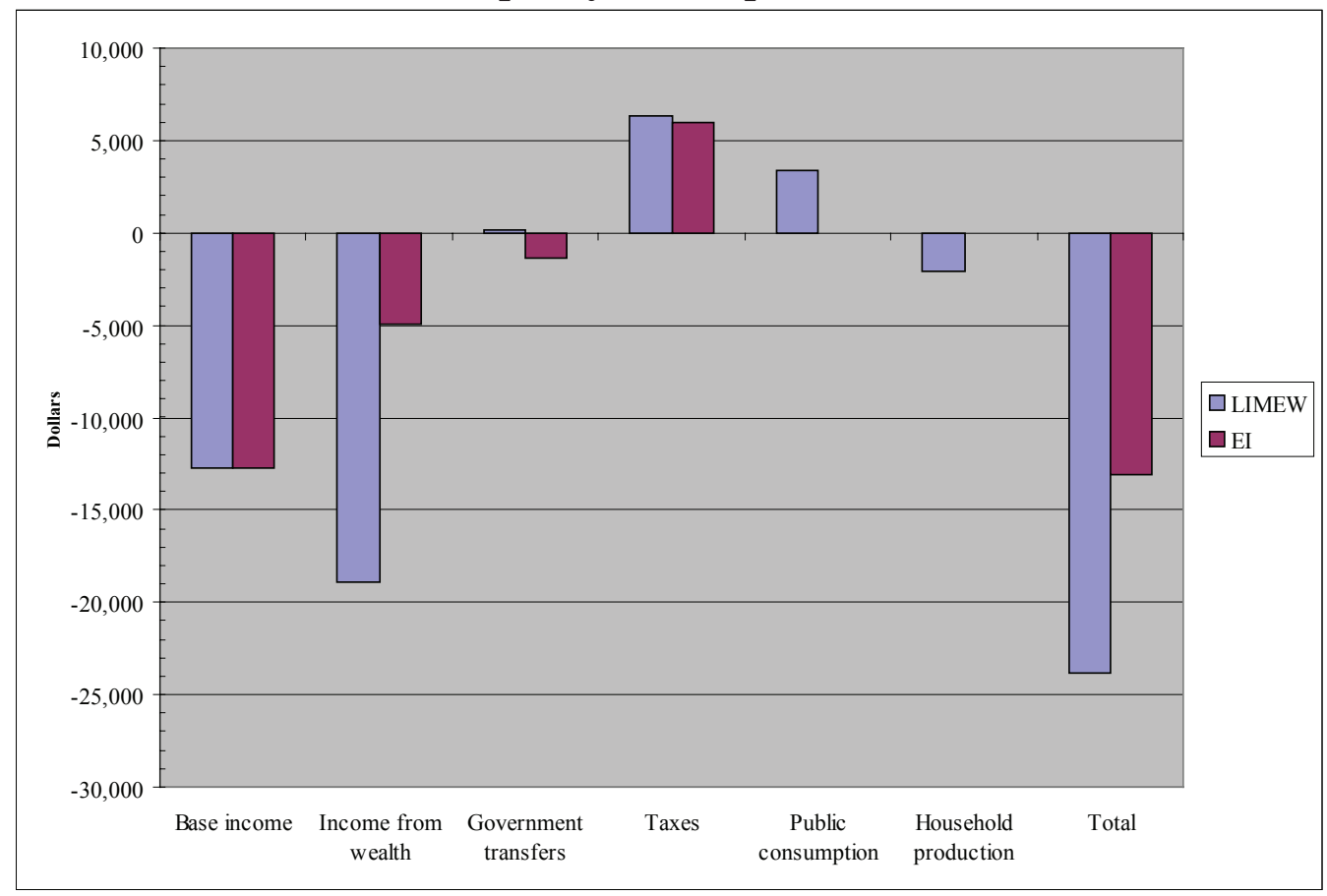


nonwhite disadvantage in EI appears to be identical to the deficit in base income, with the higher amount of taxes that the white households pay canceling out their advantage in income from wealth in EI. In contrast, income from wealth in the LIMEW is much higher for whites-the gap is $\$ 19,000$ in the LIMEW versus $\$ 5,000$ in EI-and explains why the gulf between the two groups in the LIMEW is significantly larger. It is also of note that public consumption favors nonwhites more than whites, largely reflecting the higher educational expenditures incurred on their behalf due to the higher number of children in the average nonwhite household. On the other hand, the value of household production is higher for whites as a result of two reasons: (i) the average hours of housework done by all adults are higher for white households because of the higher number of adults in the average white household; and, (ii) the hourly replacement cost of household production is higher for white households because of their higher average money income and educational attainment. Taken together, the nonwhite-white differences in the imputed value of the two types of nonmarket provisioning appear to be similar in size and hence their combined effect on the nonwhite-white LIMEW gap is quite small.

We now turn to disparities among three subgroups based on marital status and sex of the householder. ${ }^{10}$ All three measures show a very high gap in well-being between families with a single-female householder ("single females") and families with a married householder ("married couples") and a slight widening of the gap in 2001 as compared to 1989. In 2001, single females had an average money income that was only half of the married couples; EI and the LIMEW paint a slightly better picture since the ratios of mean values between single females and married couples are, respectively, 0.57 and 0.56 . The disadvantage in well-being faced by families with a single-male householder ("single males") relative to married couples is considerably less than the disadvantage faced by single females according to all three measures. In 2001, single males had an average well-being that was roughly 70 percent of married couples.

The distinct roles played by the individual components in shaping the absolute gap between single females and married couples in the LIMEW and EI are highlighted in Figure 3B. In 2001, as compared to married couples, the average LIMEW for single females was lower by roughly $\$ 55,000$ and EI was lower by about $\$ 30,000 .{ }^{11}$ The disadvantage of single females in base income $(\$ 37,000)$ alone exceeds their shortfall in EI. This is further exacerbated by their lower income from wealth as measured in EI. The gap between the two subgroups in EI is moderated to a much larger extent by taxes rather than government expenditures. The sources of disparity between the two groups in the LIMEW appear to be considerably different. Firstly, income from wealth in the LIMEW is much higher for married couples-the gap is $\$ 26,000$ in the LIMEW versus $\$ 7,000$ in EI. Secondly, the extent to which government expenditures favor single females over married couples is noticeably higher in the LIMEW- the extra expenditures is over $\$ 7,000$ in the LIMEW versus a mere $\$ 308$ in EI. This is mainly due to the presence of public consumption in the LIMEW. Finally, married couples have a substantially higher value of household production (the gap amounts to about $\$ 14,000$ ) reflecting their higher average hours of housework and higher hourly replacement cost.

We end our discussion of subgroup disparities by examining the gaps in well-being between households with householders belonging to four age groups. The hump 
FIGURE 3A

Disparities between Types of Families, 1989 and 2001

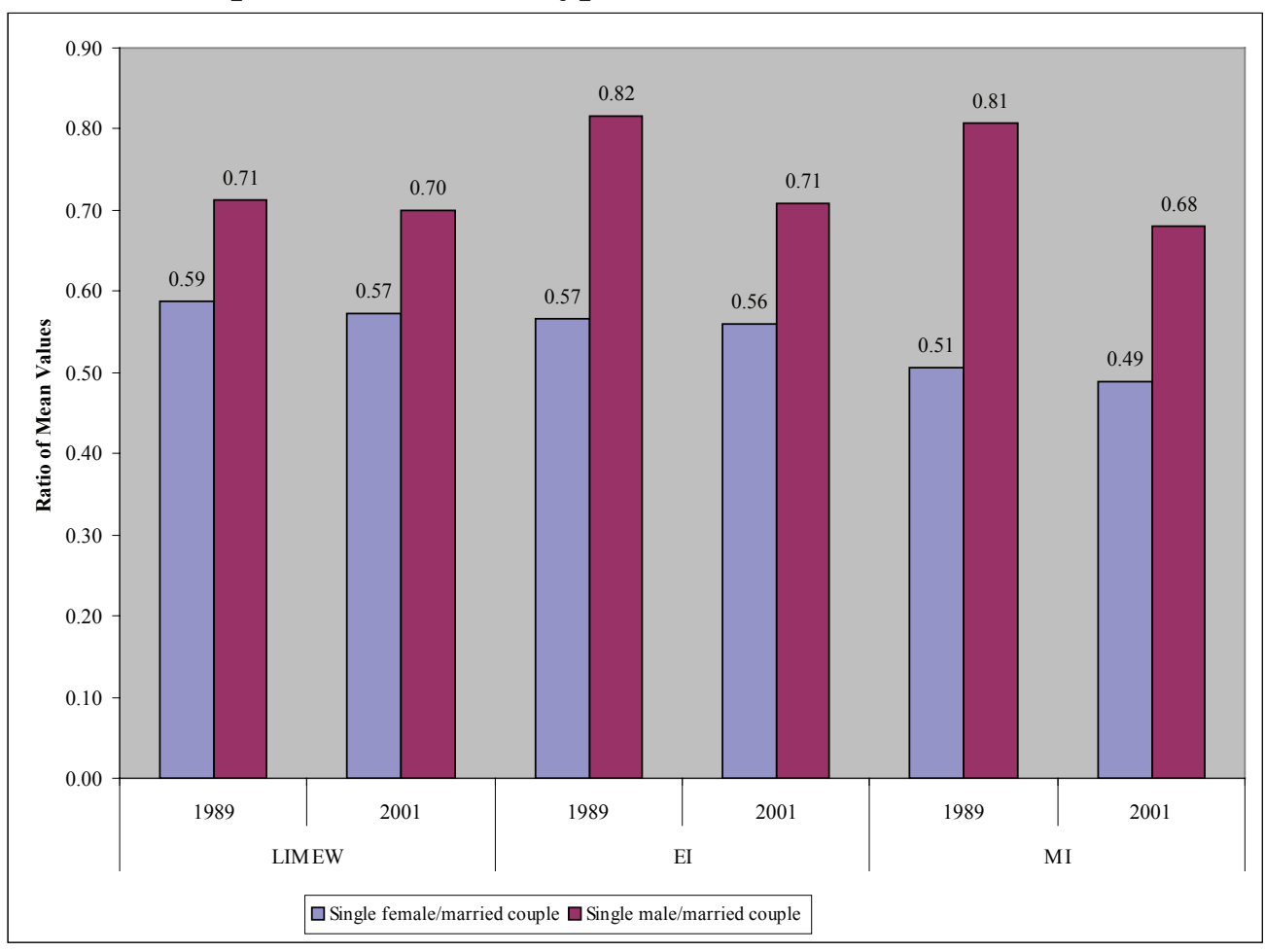

FIGURE 3B

Disparities between Single Female-Headed Families and Married-Couple Families in Components, 2001

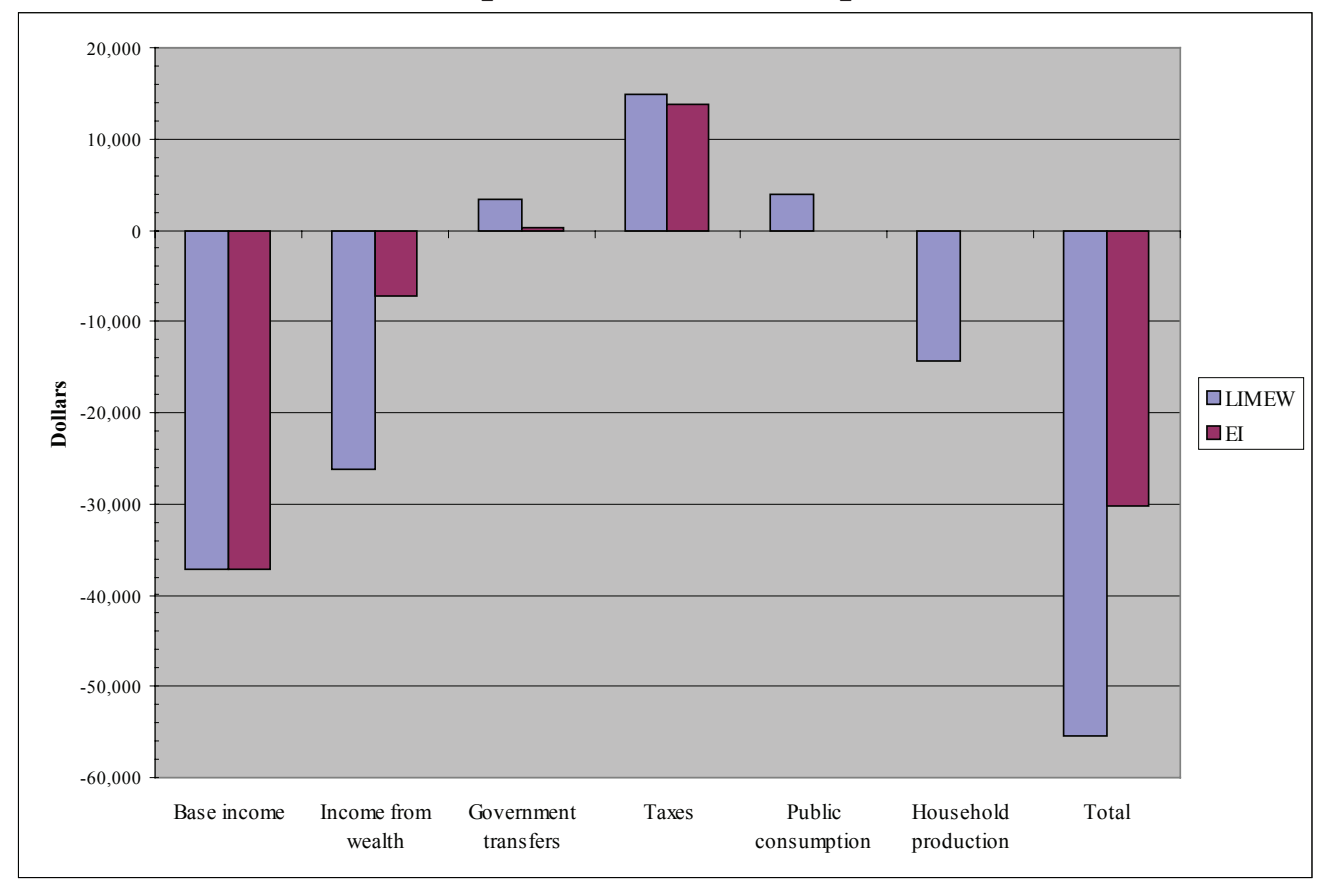


shape of the age-income relationship (i.e., the 35-64 age group is better off, while the youngest and oldest age groups are worse off, compared to the average) appears to hold for the official measures, but not for the LIMEW (Figure 4A). The relationship breaks down for the LIMEW not because the youngest have a higher relative well-being, but because the elderly finds itself with a somewhat higher relative well-being. The mean LIMEW for the elderly was 7 percent higher than the average LIMEW for all households. In contrast, the average well-being of the elderly was 77 percent of all households according to EI and only 60 percent according to MI.

In absolute terms, the elderly fell behind the average household by nearly $\$ 12,000$ in EI while they were ahead of the average household by about $\$ 7,000$ in LIMEW (Figure 4B). The difference regarding the picture of the relative well-being of the elderly mainly stems from the manner in which income from wealth is reckoned in the two measures. The LIMEW includes the annuity value from nonhome wealth as income, which is quite high for the elderly owing to a greater amount of accumulated wealth and a shorter remaining life expectancy. As a result, the wealth advantage of the elderly is more prominent in the LIMEW ( $\$ 26,000$ more than the average household) than in EI $(\$ 3,000)$. The other components that are common to both measures-base income, transfers and taxes-have similar and predictable effects on the age gap in well-being. Base income is the largest contributor to the gap in both measures, with the average household earning $\$ 36,000$ more than the elderly household. Transfers, on the other hand, help raise the well-being of the elderly much more than they do so for the average households, reflecting the large share of age-based entitlement programs (Social Security and Medicare) in total transfers. Taxes fall much more on the average household than on the elderly because of the former's larger taxable income. However, net government expenditures and income from wealth in EI are together only able to reduce, but not eliminate, the disadvantage of the elderly relative to the average household in EI. Even though household production and public consumption favor the average household more than the elderly, the latter's substantial advantage in income from wealth along with favorable net government expenditures helped to put them a little ahead of the average household in terms of the LIMEW.

\section{ECONOMIC INEQUALITY}

Our understanding of the degree of inequality in well-being and its changes over time depends significantly on how we measure well-being. In this section, we will describe the extent to which the level of inequality differs among the various measures. Our indicator of inequality will be the Gini coefficient. ${ }^{12}$ We will also discuss, using decomposition analysis, how the relative importance of the constituent components of the LIMEW and the most comprehensive official measure, EI, differ in determining the changes in inequality (e.g., how much did base income contribute to the change in inequality in the LIMEW versus the change in inequality in EI?). The decomposition analysis will also allow us to provide estimates of the incremental effects of the various components (i.e., how much does a small proportionate change in base income contribute to a change in overall inequality?) and how these effects vary between the LIMEW and EI. 
FIGURE 4A

Disparities between Age Groups, 2001

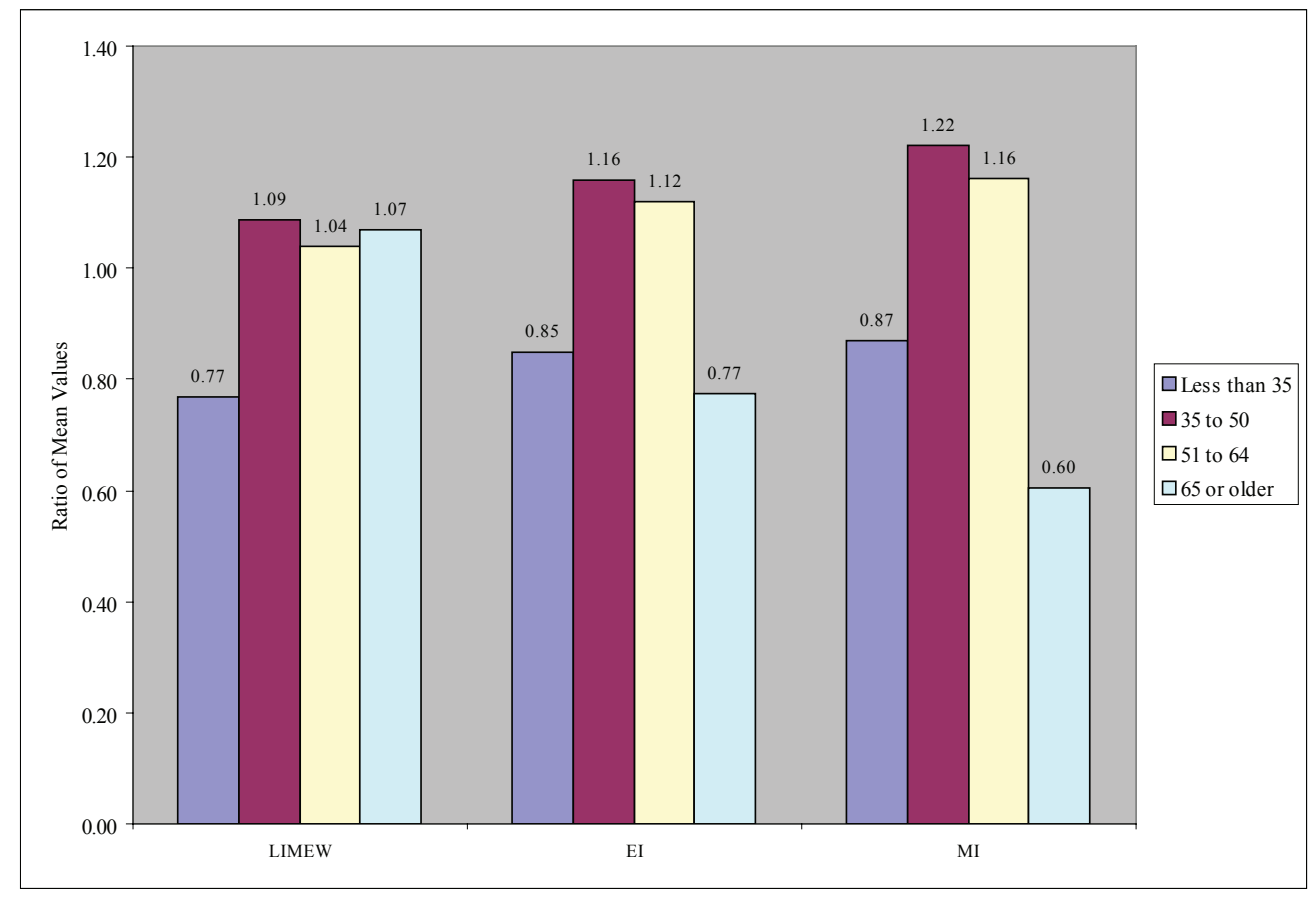

FIGURE 4B

Disparities between the Elderly and Average Household in

Components, 2001

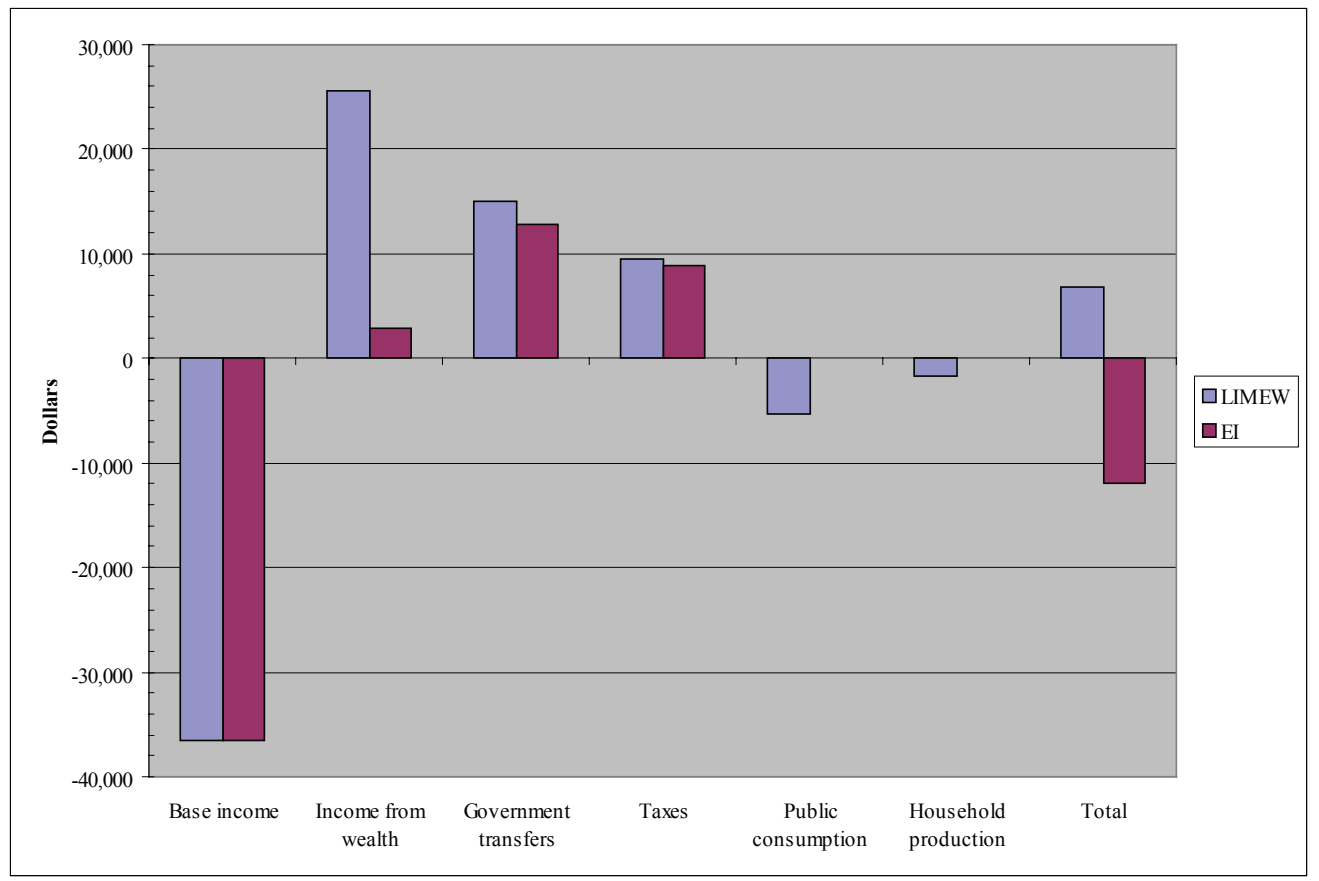


However, before we embark on an examination of the Gini coefficients, it is perhaps useful to begin with an overview of the shares of each quintile in aggregate income (Table 5). The quintiles of each income measure are defined by ranking households according to the amount of that income. Therefore, in general, a given quintile of the different measures need not be made up of the same households. Nevertheless, it is striking that according to all three measures, the only quintile that experienced an increase in their share of aggregate income between 1989 and 2001 was the top quintile. The extent of the increase in the top quintile's share was most pronounced in the LIMEW (4.6 percentage points), followed by MI (4.4) and EI (3.1). As for their shares in the overall pie, the top quintile fared the best according to MI with a share of 50 percent in 2001; the top quintile of the LIMEW had a slightly lower share of 48.3 percent while the top quintile of EI had an even lower share of 45 percent. Among the three measures, the share of the bottom quintile is the highest in the LIMEW (5.3 percent), followed by EI (4.5) and MI (3.5).

TABLE 5

Share of Each Quintile in Aggregate Income, 1989 and 2001

\begin{tabular}{llrccc}
\hline \multicolumn{5}{c}{ Quintiles } \\
\hline \multicolumn{1}{l}{$\mathbf{1 9 8 9}$} & $\mathbf{1}$ & $\mathbf{2}$ & $\mathbf{3}$ & $\mathbf{4}$ & $\mathbf{5}$ \\
LIMEW & & & & & \\
MI & 6.1 & 11.3 & 16.3 & 22.6 & 43.7 \\
EI & 3.9 & 9.7 & 16.2 & 24.5 & 45.6 \\
$\quad \mathbf{2 0 0 1}$ & 5.2 & 11.4 & 17.1 & 24.3 & 41.9 \\
LIMEW & 5.3 & & & & \\
MI & 3.5 & 10.2 & 15.0 & 21.2 & 48.3 \\
EI & 4.5 & 8.8 & 14.7 & 23.1 & 50.0 \\
\hline
\end{tabular}

Note: Quintiles for each income measure are defined with respect to that income measure.

The rank order of the income measures according to top quintile shares are also reflected in their Gini coefficients (see Figure 5). ${ }^{13}$ In 2001, the Gini coefficient for MI was the highest at 46.4, followed by those for LIMEW (42.6) and EI (40.4). Compared to the LIMEW and EI, MI overstates inequality because it is a pretax measure that does not fully account for government transfers. Public consumption and household production are relatively less unequally distributed, and hence, their inclusion in the LIMEW also lowers the degree of LIMEW inequality relative to MI.

The official measures and the LIMEW indicate that the distribution of economic well-being was more unequal in 2001 than in 1989. The inequality in LIMEW showed a greater increase between the two years (5.1 Gini points) than in EI (3.5) and MI (4.6). According to the official measures, most of the increase in inequality occurred during the first half of the 1990s while the increase in LIMEW inequality appears to be more evenly spread between the subperiods 1989-1995 and 1995-2001. The higher growth in LIMEW inequality is especially interesting because it cannot be accounted for solely by rising earnings inequality, the main factor behind the changes in MI and EI inequality. ${ }^{14}$ Since the gap between the Gini coefficients for the LIMEW and EI are quite close in 1989 (a difference of only 0.6 Gini point) and quite apart in 2001 (a difference of 2.2 Gini points), it would be instructive to examine how the individual 
components shaped the overall inequality in the two measures over the 1990 s. We present the results from decomposition analysis for this purpose, with the caveat that such analysis is not a substitute for a full causal analysis, but only a useful starting point.

FIGURE 5

Inequality by Measure, 1989 to 2001 (Gini coefficient x 100)

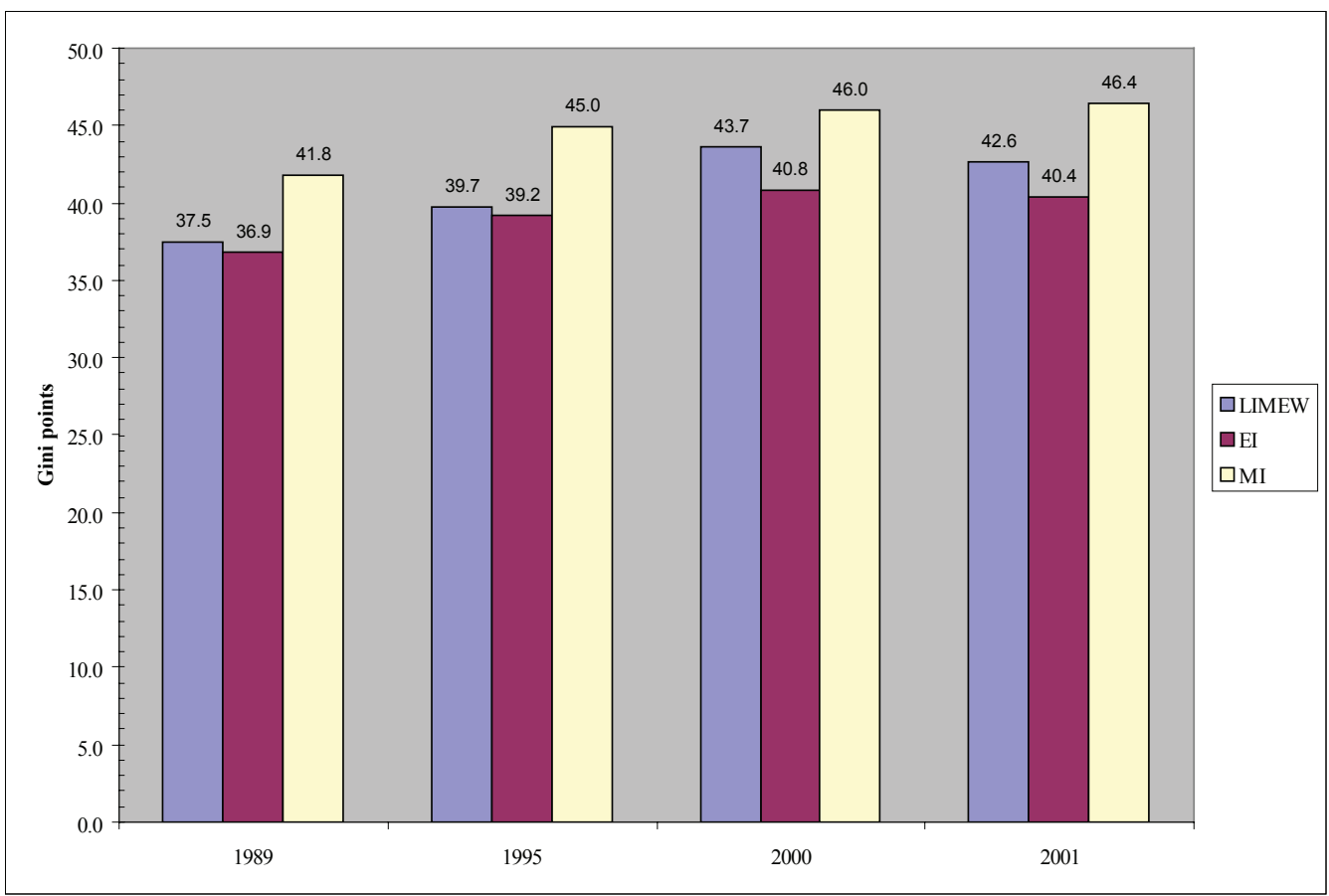

The idea behind the decomposition analysis is to express the Gini coefficient of an income measure as the sum of the "contributions" made by its components [Lerman, 1999]. We denote $y$ as the income measure and number its components $1,2, \ldots, k$ so that $y=\sum_{i=1}^{k} y_{i}$. Let $g_{y}$ denote the Gini coefficient. Then, the decomposition is $g_{y}=\sum_{i=1}^{k} b_{i}$, where $b_{i}$ is the contribution to the Gini made by the component $y_{i}$. In turn, a component's contribution is calculated as the product of its concentration coefficient $\left(c_{i}\right)$ and its share in total income $\left(s_{i}\right): b_{i}=c_{i} s_{i}$ [Yao, 1999, 1252-53]. ${ }^{15}$ The results of the decomposition analysis for 1989 and 2001 are shown in Table 6.

In order to uncover the proximate causes of the growth in LIMEW inequality outstripping the growth in EI inequality, we calculated, from the numbers in Table 5, the changes in the contribution made by individual components to the total change in the Gini for each measure (Figure 6). Quite clearly, the major drivers of the changes in inequality are different in the two measures. Base income played this role in EI while income from wealth is the major factor behind the changes in LIMEW inequality. The difference in their respective roles is, in turn, due to the divergent movement in their shares in income that we already discussed in connection with the composition of the LIMEW and EI (see the discussion of results in Table 3). The share of base income in EI rose from 95.5 percent in 1989 to 99.8 percent in 2001, while the 
share of income from wealth in EI declined from 18.3 percent in 1989 to 16.1 percent in 2001. The opposite pattern prevailed for the LIMEW: the share of base income declined from 57.5 percent in 1989 to 55 percent in 2001, while the share of income from wealth rose sharply from 18.3 percent in 1989 to 23 percent in 2001 , mainly due to the growth in annuities. The latter reflected the sharp growth in nonhome wealth during the period.

TABLE 6

Decomposition of Inequality by Income Source, 1989 and 2001

\begin{tabular}{|c|c|c|c|c|c|c|}
\hline & \multicolumn{3}{|c|}{1989} & \multicolumn{3}{|c|}{2001} \\
\hline & $\begin{array}{l}\text { Contribution } \\
\text { (Gini points) }\end{array}$ & $\begin{array}{l}\text { Share in } \\
\text { income } \\
\text { (percent) }\end{array}$ & $\begin{array}{l}\text { Share in } \\
\text { inequality } \\
\text { (percent) }\end{array}$ & $\begin{array}{l}\text { Contribution } \\
\text { (Gini points) }\end{array}$ & $\begin{array}{l}\text { Share in } \\
\text { income } \\
\text { (percent) }\end{array}$ & $\begin{array}{l}\text { Share in } \\
\text { inequality } \\
\text { (percent) }\end{array}$ \\
\hline \multicolumn{7}{|l|}{ LIMEW } \\
\hline Base income & 20.9 & 57.5 & 55.6 & 21.0 & 55.0 & 49.2 \\
\hline Income from wealth & 12.6 & 18.3 & 33.7 & 17.3 & 23.0 & 40.6 \\
\hline Imputed rent & 2.0 & 4.5 & 5.3 & 1.7 & 3.6 & 4.0 \\
\hline Annuities & 10.6 & 13.7 & 28.3 & 15.6 & 19.3 & 36.6 \\
\hline Net government expenditures & -4.2 & 1.4 & -11.2 & -3.6 & 0.9 & -8.4 \\
\hline Transfers & 0.2 & 9.0 & 0.5 & 0.8 & 9.5 & 1.8 \\
\hline Public consumption & 2.3 & 9.4 & 6.1 & 2.4 & 9.0 & 5.6 \\
\hline Taxes & -6.6 & -17.1 & -17.7 & -6.7 & -17.6 & -15.8 \\
\hline Household production & 8.2 & 22.9 & 21.9 & 7.9 & 21.1 & 18.6 \\
\hline Total & 37.5 & 100.0 & 100.0 & 42.6 & 100.0 & 100.0 \\
\hline \multicolumn{7}{|l|}{ Extended Income } \\
\hline Base income & 41.2 & 95.5 & 111.6 & 46.5 & 99.8 & 115.2 \\
\hline Income from wealth & 9.7 & 18.3 & 26.4 & 8.6 & 16.1 & 21.2 \\
\hline Return on home equity & 3.0 & 7.7 & 8.2 & 1.4 & 5.4 & 3.5 \\
\hline $\begin{array}{l}\text { Property income plus realized } \\
\text { capital gains }\end{array}$ & 6.7 & 10.6 & 18.2 & 7.1 & 10.7 & 17.7 \\
\hline Net government expenditures & -14.0 & -13.8 & -38.0 & -14.7 & -15.9 & -36.4 \\
\hline Transfers & -0.7 & 11.4 & -1.8 & 0.0 & 12.4 & -0.1 \\
\hline Taxes & -13.3 & -25.2 & -36.2 & -14.7 & -28.3 & -36.3 \\
\hline Total & 36.9 & 100.0 & 100.0 & 40.4 & 100.0 & 100.0 \\
\hline
\end{tabular}

Note: See text for an explanation of calculation methods

Thus, the difference in the manner in which income from nonhome wealth is reckoned in the two measures serves as the main explanation for the faster growth in LIMEW inequality. The difference suggests that considering changes in economic inequality to be shaped, basically, by earnings inequality (the main component of base income) may be misleading. Wealth inequality also plays an important role.

The results of the decomposition analysis also reveal that the part played by net government expenditures in determining the level and trend of inequality is quite different between the LIMEW and EI. Net government expenditures considerably reduce the overall level of inequality in the LIMEW and EI (the share of net government expenditures in inequality is negative and large, see Table 6). However, the effect of net government expenditures is much larger in EI (-36.4 percent in 2001), as compared to the LIMEW (-8.4 percent). This difference is mainly due to the inclusion of public consumption in the LIMEW on the government expenditures side, in addition to government transfers, thereby making the share of net government expenditures in the LIMEW a 
small positive number (0.9 percent in 2001). In contrast, the EI recognizes only transfers as government expenditures benefiting the household and hence the share of net government expenditures in EI was a large negative number (-15.9 percent in 2001).

\section{FIGURE 6 \\ Contribution of Each Component to the Change in Gini, 1989 to 2001}

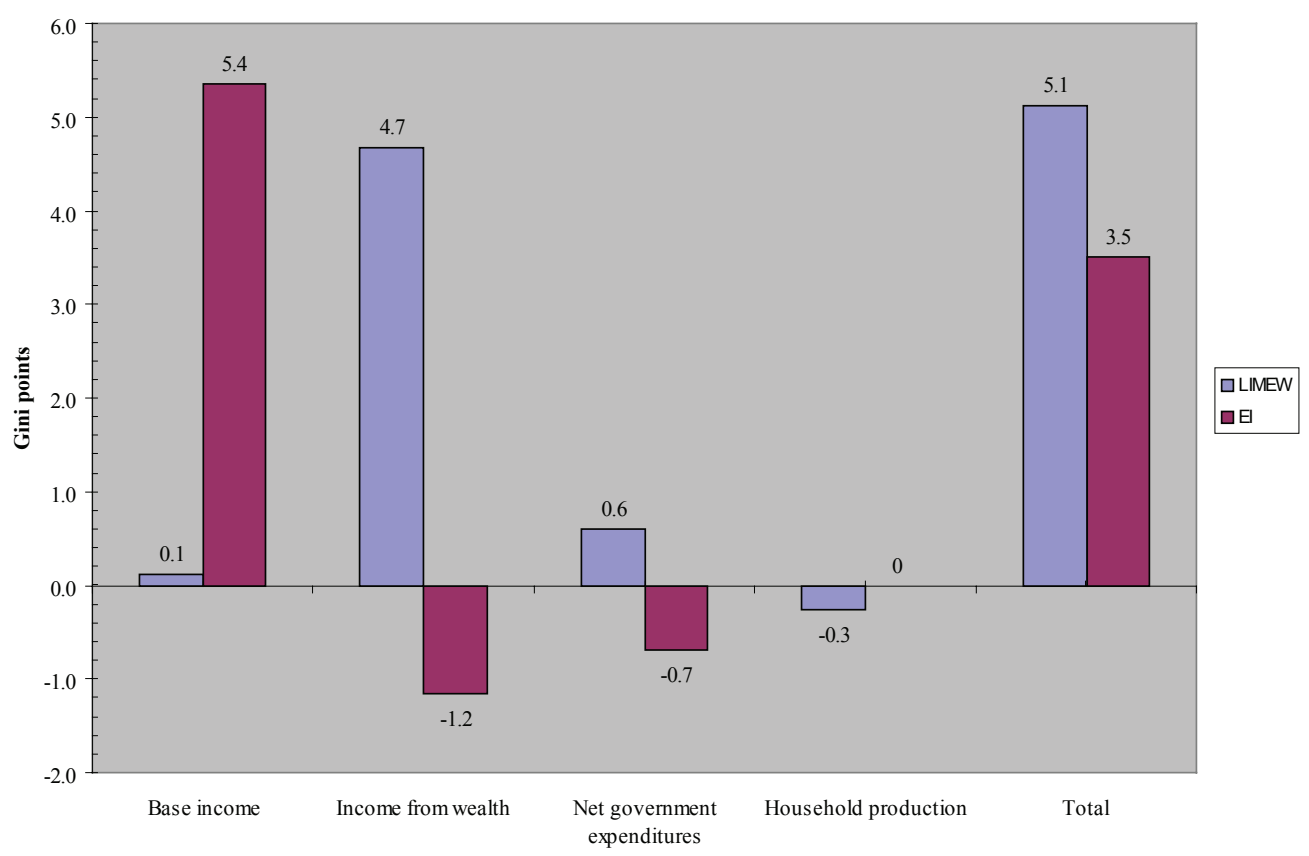

Since policy changes in the mix of expenditures and taxes typically operate at the margin, it is also useful to look at the incremental effects of these components on LIMEW and EI inequality. The incremental effect of a particular component on inequality refers to the proportionate change that occurs from a hypothetical, small proportionate change in that component, everything else remaining the same. ${ }^{16}$ Since "everything else" does not remain the same, these estimates should be considered a rough indication of the relative effects of potential policies on inequality.

The incremental effect of net government expenditures on inequality appears to be overstated in EI relative to the LIMEW (Figure 7). Both taxes and expenditures reduce EI inequality at the margin. While the inequality-reducing effect of expenditures on LIMEW is roughly the same as that on EI, taxes have a negligible effect, in sharp contrast to their effect on EI inequality. The differential impact of taxes on the two measures is due to the differential relationship between taxes and income at the top of the distributions. Households at the top of the EI distribution have taxable income as the main source of their income and, therefore, effective tax rates rise as we move to higher income levels. In contrast, households at the top of the LIMEW distribution have imputed income from wealth (obviously not subject to taxation) as a very sizeable portion of their LIMEW. ${ }^{17}$ Hence the positive relationship between tax rates and income breaks down at the top of the LIMEW distribution. As a result, a small proportionate 
increase in taxes for all households will slightly reduce the share in aggregate LIMEW of those below the very top and lead to a small increase in overall inequality.

\section{CONCLUSION}

The picture of economic well-being is crucially dependent on the yardstick used to measure it. Although gross money income (MI), the most widely used official measure, may be suitable for certain purposes, it is an incomplete measure in several important ways. The elevation of more comprehensive measures to a status that is on par with MI in the official scorecard of the economic well-being of U.S. households is a sure indication that academic discussion and policy making will be increasingly informed by such measures.

The LIMEW is different in scope from the official measures. Our measure recognizes that economic well-being depends on public and self provisioning, in addition to the command over commodities. In contrast, the official measures are restricted to measuring the latter. Because we believe that these components are important, we have developed a set of estimates that reflect their effect and significance. The LIMEW differs from the official measures also in its methods, especially in our treatment of income from wealth and noncash transfers (see Table 1). These differences are more than formulae, since they are the result of alternative concepts of economic well-being [Wolff, Zacharias, and Caner, 2004, 7:9; Wolff and Zacharias, 2003].

The differences in scope and method lead to substantially different findings regarding economic well-being. The median U.S. household appears to be much better off in 2001 than in 1989 according to our measure relative to the official measures. The mean value of the LIMEW also showed a much higher growth over the same period than the official measures. It appears that the main factor behind the measured differences in the trend of economic well-being is the differences in the composition of the measures. While the composition of the LIMEW has changed in favor of income from wealth, there has been no such change in the most comprehensive official measure, EI. However, the compositional change over the 1990s differed between the top and bottom quintiles of the LIMEW. Households at the bottom have become more reliant on base income (mainly consisting of labor income) and less on net government expenditures. On the other hand, for those at the top, income from wealth has become significantly more important than base income.

The LIMEW also provides a different picture of disparities among population subgroups. Racial disparities have increased between 1989 and 2001 according to the LIMEW, while the official measures show slight improvement. The worsening of the racial gap is traceable, mainly, to the considerable and growing disadvantage faced by nonwhites in wealth ownership. As for single females, the LIMEW and the official measures show a very high gap in well-being between them and married couples. However, the sources of disparity between the two groups in the LIMEW appear to be considerably different as it is shaped by the complex interaction of advantages and disadvantages in income from wealth, net government expenditures and household production. In contrast, the disparity between the groups in EI is largely a reflection of the gaps in their labor income. The hump shape of the age-income relationship (i.e., 
the 35-64 age group is better off, while the youngest and oldest age groups are worse off, compared to the average) appears to hold for the official measures, but not for the LIMEW. The elderly are slightly better off than the average household in 2001 because of greater income from wealth owing to a greater amount of accumulated wealth and a shorter remaining life expectancy. Our results suggest that the relevant problem, both analytically and in terms of public policy, is to investigate the forces behind the disparities in individual components, which we plan to address in future research.

The differences with respect to which components and how they are included in the measure of well-being also play a crucial role in the analysis of overall economic inequality. While all measures considered here indicate a growth in inequality over the 1990s, the LIMEW shows the largest increase. Decomposition analysis suggested that the higher growth in LIMEW inequality is due to the sharp growth in the contribution to inequality made by income from wealth. The latter reflected the solid growth in nonhome wealth over the 1990s, especially for those at the top of the LIMEW distribution. Our analysis also indicates that while net government expenditures have an inequality-reducing effect for both measures, the EI overstates the effect, as compared to the LIMEW. A more important finding from a policy standpoint, perhaps, is the asymmetric incremental effect of taxes on inequality between the two measures: Taxes have a large negative effect that is similar to government spending in EI, while government spending appears to have a much larger inequality-reducing effect than taxes in the LIMEW.

Several issues related to economic well-being require further research and evaluation. We hope that our analysis will lead to further academic and policy research and will stimulate a rethinking of public policies that affect well-being.

\section{APPENDIX: SOURCES AND METHODS}

\section{Introduction}

Our main data source is the public-use data files developed by the U.S. Bureau of the Census from the Current Population Survey's Annual Demographic Supplement (ADS), which is the most comprehensive source of annual information regarding household income, housing tenure, receipt of noncash transfers, and a number of key demographic characteristics of U.S. households. The number of households was 59,941 in 1989 and 78,265 in 2001. The ADS contains either partial or no information on imputed income from wealth, government transfers, public consumption, taxes, and household production. Therefore, we impute values for these components based on additional information.

The component of the LIMEW that is also part of the official definition of money income is called "base money income"-money income less property income (the sum of dividends, interest, and rent) less government cash transfers, as reported in the ADS. Roughly 95 percent of base money income consists of earnings. Another component of the LIMEW that is taken directly from the ADS (though not included in the official measure of income) is the imputed value of employer contributions to health insurance. Our estimation of the remaining five components of the LIMEW is briefly described below. 


\section{Imputed Income from Wealth}

Our data source for household wealth is the 1989, 1995 and 2001 waves of Survey of Consumer Finances (SCF), conducted by the Federal Reserve Board. For these years the survey collected data for 3,134 and 4,442 households, respectively. We use marketable wealth (or net worth) as our wealth concept, which is defined as the current value of all marketable or fungible assets less the current value of debts. Total assets are the sum of (1) the gross value of owner-occupied housing; (2) other real estate owned by the household; (3) cash and demand deposits; (4) time and savings deposits, certificates of deposit, and money market accounts; (5) government bonds, corporate bonds, foreign bonds, and other financial securities; (6) the cash surrender value of life insurance plans; (7) the cash surrender value of pension plans, including IRAs, Keogh, and 401(k) plans; (8) corporate stock and mutual funds; (9) net equity in unincorporated businesses; and (10) equity in trust funds. Total liabilities are the sum of mortgage debt, consumer debt (including auto loans), and other debt.

We assign net worth by statistical matching to the households in the ADS. Each household record in the SCF is matched with a household record in the ADS, where a match represents a similar unit. The strata variables used in the matching procedure are race of the household head (white versus nonwhite), homeownership status of the household (owner or buyer versus renter), family type (married couple, single male, or single female), and age of the household head (age differences within a range of two, five, and ten or more years). Within these strata, records are matched by minimizing a distance function based on education and occupation of the household head and total income and size of the household. The weights of the distance function are the coefficient estimates from an OLS regression of net worth that includes, as regressors, all of the variables mentioned above.

Home and nonhome wealth are treated separately in the imputation process. In the case of home wealth, imputed rent is the replacement cost of services derived from owner-occupied housing. We estimate this amount by distributing the total amount of imputed rent on nonfarm, owner-occupied housing in the GDP [NIPA table 8.21, line $172]$ to homeowners in the ADS based on the (gross) imputed value of their houses. In the case of nonhome wealth, we estimate the constant lifetime annuity flow generated by each nonhome wealth component using average total real rates of return for each component from 1960 to 2000. In the next step we calculate the weighted sum of the annuity flows for each household with the portfolio shares of the components serving as weights. The annuity amount calculated is such that nonhome wealth is exhausted at the end of the wealth-holder's life. ${ }^{18}$

\section{Government Transfers}

Government transfers in the LIMEW are "NIPA consistent," in the sense that, in aggregate, they are equal to the appropriate NIPA benchmarks, after adjusting for differences in definition and coverage [Wolff, Zacharias, and Caner, 2004, 21].

Transfers for which actual or imputed amounts are reported in the ADS are aggregated across recipients and compared against the benchmarks. ${ }^{19}$ Any discrepancy 
between the ADS total and the NIPA benchmark for a given transfer payment is distributed across recipients according to the distribution of that payment in the ADS.

Transfers for which there are no actual or imputed amounts reported in the $\mathrm{ADS}$ can be divided into two categories: those where recipients are identified in the ADS itself, and those where we imputed recipiency. The first category consists of the noncash component of public assistance; the Women, Infants, and Children (WIC) program; and employment and training. Noncash public assistance is distributed across households according to the number of "cases" per household (the sum of those reporting cash public assistance, of children receiving publicly assisted childcare, and of those reporting receipt of transportation assistance). Expenditures on WIC are distributed equally among the recipients. Expenditures on employment and training are distributed equally among those receiving job training or attending school to get the General Equivalency Diploma (GED). The second category consists of militaryrelated transfers (veterans' life insurance, medical payments for retired and active armed forces personnel and their dependents at nonmilitary facilities), and payments to nonprofit institutions. Potential beneficiaries from military-related transfers are identified using demographic information from the ADS, and these expenditures are divided equally among the beneficiaries. Payments to nonprofit institutions are assumed to be incurred on behalf of the entire population and distributed equally.

All of the transfers discussed in the previous paragraph (with the exception of the noncash component of public assistance, which did not exist at the time) had to be distributed on the basis of imputed recipiency in 1989 and 1995, because the survey did not ask recipiency questions. To identify the potential WIC beneficiaries, we approximated the federal eligibility criteria (families with income up to 185 percent of the poverty-line and with children under 6 years of age) and divided the expenditures equally among them. Expenditures on employment and training were divided equally among adults receiving cash public assistance and those in training, but wanting a regular job.

\section{Public Consumption}

Estimates of public consumption by households were constructed in three steps: (1) obtaining total expenditures by function and level of government; (2) allocating total expenditures between the household sector and other sectors of the economy; and (3) distributing expenditures allocated to the household sector among households.

\section{Expenditure by Function and Level of Government.}

The expenditure category used here is government consumption expenditures and gross investment (the same as that on the product side of the NIPA). To group expenditures according to purpose, we adopted the functional classification in NIPA with minor modifications.

We distributed the NIPA aggregate of state and local expenditures for each function among the states using the interstate distribution of these expenditures in the Annual Survey of Government Finances (ASGF) conducted by the U.S. Bureau of the Census in 1989 and 2000. Care was taken to ensure that the expenditure concept and 
the groupings of the functions in the ASGF conform as closely as possible to the NIPA expenditure and function concepts.

\section{Allocation of Expenditures to the Household Sector.}

We started by constructing a schema of 44 functions by level of government (federal versus state and local). ${ }^{21}$ Then, we grouped these functions into three categories. The first involved activities that do not expand the potential amenities available to the household sector. General public service, national defense, law courts and prisons are prominent examples. The second category included functions that are assumed to expand amenities directly only to the household sector, such as income security and recreation and culture.

The third category consisted of functions that can potentially serve both the household and nonhousehold sectors, such as economic affairs and housing and community services. Costs incurred in the performance of these functions are allocated to the household sector in accordance with the extent that they are "responsible" in generating such costs. Our judgment regarding the extent of responsibility is based on the available empirical information, as much as possible. A prominent example of this type of function is highways (included under economic affairs), where approximately 60 percent of expenditures were estimated to occur on behalf of households.

\section{Distribution of Allocated Expenditures among Households.}

After determining government expenditures allocated to the household sector (i.e., "public consumption") by function, we distributed them among households. We attempted to follow the same principles of direct usage and cost responsibility that were employed in splitting total government expenditures between the household and nonhousehold sectors. Two major categories of public consumption are distributed among households: those distributed equally across persons (such as public health and hospitals, police and fire) and those distributed according to household-level, or personlevel, characteristics (such as elementary and secondary education, highways).

The second group of expenditures account for the bulk of public consumption (nearly three-quarters). The person-level or household-level characteristics used in the distribution procedures, and their corresponding functions, are listed below:

- Amount and type of income: agriculture.

- Type of income received (including receipt of noncash transfers): public housing, administrative costs of Medicare, disability, retirement income (Social Security), welfare and social services, and unemployment compensation.

- Shares in consumption expenditures: energy, pollution control and abatement, postal service, liquor stores, water supply, sewerage and sanitation.

- Enrollment in public educational institutions: education.

- Patterns of vehicle ownership and transportation usage: transportation and parking.

- Employment status: occupational safety and health.

Information on the type and amount of income, as well as the employment status of individuals, is obtained directly from the ADS. All other characteristics were imputed to individuals or households in the ADS sample from information gathered from external sources. 


\section{Taxes}

The estimated household tax burden in the LIMEW consists of federal and state individual income taxes, property taxes on owner-occupied housing, payroll taxes (employee portion), and state and local consumption taxes (excise and sales). All taxes, apart from consumption taxes, have imputed values in the ADS and were aligned with their NIPA counterparts by distributing for each tax the discrepancy between the NIPA and ADS aggregate among households according to the share of each household in the ADS aggregate.

State and local consumption taxes are calculated on the basis of estimates published by the Institute on Taxation and Economic Policy [McIntyre et al., 2003]. The publication contains average state tax rates for "General Sales-Individuals" and "Other Sales and Excise-Individuals" differentiated for households in each quintile of the household income distribution and in selected portions of the top quintile. We assigned these average tax rates to households in the corresponding positions in the ADS household income distribution. The resulting tax aggregates were lower than the NIPA counterparts. Since we had no independent estimate of the household shares in the NIPA totals, it was impossible to align the household consumption tax burden with any portion of the NIPA.

\section{Household Production}

Our data sources for household production are the Americans' Use of Time Project (AUTP) conducted in 1985, Family Interaction, Social Capital, and Trends in Time Use Study (FISCT) conducted during the 1998-99 period and the American Time Use Survey (ATUS) conducted in 2003. The first two surveys were undertaken at the Survey Research Center, University of Maryland. These surveys used the time-diary method and collected time use, demographic, and economic data for 5,358 and 1,151 individuals, respectively. ATUS was conducted by the Bureau of Labor Statistics and had a sample size of approximately 20,000 individuals. The list of activities allowed us to estimate the total time spent on paid work and on the three main household production activities: core production (such as cooking and cleaning), distribution (such as shopping for groceries), and childcare (such as caring for babies and reading to children).

Our imputations are based on the AUTP data for 1989, the FISCT data for 1995, and the ATUS for 2000 and 2001. We statistically matched each adult record in the time-use survey to an adult record in the ADS. Men and women were matched separately, because the effects of match variables on the time spent on household production vary significantly by sex. The strata variables used in the matching procedure are the dummy variables for being employed and for being a parent. Within these strata we match records by minimizing a distance function based on the number of children under five and dummy variables for marital status, unemployment, age, education, retirement, being a homemaker (for women). The weights of these variables in the distance function are the coefficient estimates in a Tobit regression of weekly hours of housework on all the variables listed above. Weekly hours were calculated by multiplying the reported daily hours by 7 and applying "day weights" available 
from the time-use surveys to adjust the reported hours for the day of the week that the respondent filled out the time diary.

To impute the value of household production, we used the average hourly wage rate for private household employees, which was calculated from the annual file that was created by merging the Current Population Survey's monthly outgoing rotations files. The wage rate was defined as usual weekly earnings divided by usual weekly hours of work.

We attempted to capture the differences in the quality and efficiency of housework across households by constructing for each adult in the ADS a performance index that consists of years of education, household income, and time availability for housework. ${ }^{20}$ The hourly wage rate of private household employees was multiplied by this index to derive an estimate of hourly replacement cost for each adult's housework. The annual value of household production for each adult was then calculated as the product of the individual's hourly replacement cost and annual hours of housework. Finally, the imputed value of household production at the household level was derived by summing the imputed values for all adults in the household.

\section{NOTES}

Our primary debt is to Hyunsub Kum of the Levy Institute for implementing the statistical matching algorithms used in creating our synthetic data file. We gratefully acknowledge the helpful comments and advice of Dimitri Papadimitriou and Rania Antonopoulos and the able research assistance of Melissa Mahoney. We have also benefited from comments by Sheldon Danziger, Peter Gottschalk, Stephen Jenkins, David Levine, Lars Osberg, Juliet Schor, and Daniel Weinberg. Comments from two anonymous referees also helped improve the paper. We remain responsible for all errors.

1. For details regarding the data sources and methods used to estimate these components, see the Appendix.

2. This is consistent with the approach adopted in most national income accounts.

3. Our rationale for employing this method is that it is a better indicator of the resources available to the wealth holder on a sustainable basis over the expected lifetime compared to the bond-coupon method. The latter assumes away the differences in individual household overall rates of return caused by differences in household portfolios. More importantly for our purposes here, it assumes that the amount of wealth remains unchanged over the expected (conditional) lifetime of the wealth holder.

4. The rate of return used in our procedure is real total return (the sum of the change in capital value and income from the asset, adjusted for inflation). For example, for stocks, total real return would be the inflation-adjusted sum of the change in stock prices plus dividend yields.

5. In the case of Medicare and Medicaid—by far the biggest items in this list—-the relevant cost is the "insurance value" differentiated by risk classes.

6. The third-party principle is sometimes ambiguous in the case of such personal care activities as shaving (see Organization for Economic Co-operation and Development [1995, 11]).

7. In the survey, the householder is defined as the person in whose name the housing unit is rented or owned. If there is joint ownership or tenancy, one of the parties is chosen at random as the householder.

8. We prefer to use the mean values rather than median values because it allows us to decompose the difference between subgroups into individual components.

9. "Whites" are defined here as non-Hispanic whites. "Nonwhites" refer to everyone else.

10. We include only family households in this comparison, thus leaving out households with only one person and households with only unrelated individuals (e.g., roommates or unmarried partners). 
11. The size of the difference can perhaps be appreciated by considering the following statistic, based on the same survey: In 2001, the median annual earnings of average full-time, full-year, male worker were $\$ 38,275$ and the corresponding mean value was $\$ 54,061$.

12. We have examined the patterns of inequality using other indicators of inequality (e.g., the Atkinson index). However, since the patterns do not appear to be sensitive to the indicator employed, we prefer to use the most widely used indicator, i.e., the Gini.

13. The Gini coefficient is an index that ranges from zero (perfect equality) to one (maximal inequality). Here we report values that are 100 times the Gini coefficient.

14. Changes in survey design and raising the thresholds for reported earnings introduced in 1994 are estimated to raise the measured inequality in money income. One estimate is that these changes accounted for half of the increase in the inequality in household money income between 1992 and 1993 or about one Gini point [Ryscavage, 1995].

15. The concentration coefficient is similar to the Gini coefficient. The Gini coefficient is the area between the Lorenz curve and the 45-degree line multiplied by 2 , while the concentration coefficient is the area between the concentration curve and the 45-degree line multiplied by 2 . The Lorenz curve plots the cumulative proportion of income on the vertical axis and the cumulative proportion of households on the horizontal axis, with the cumulative proportions calculated after ordering households according to income (starting from the lowest and ending with the highest). Suppose we plot the cumulative proportion of a component of income (e.g., wages), keeping the same ordering of households on the horizontal axis. The curve connecting all points plotted is the concentration curve for wages.

16. The incremental effect of a component is calculated as the difference between the share of that component in inequality and its share in income.

17. According to the estimates in Table 4, the share of income from wealth in the LIMEW of the top quintile was 37.7 percent in 2001. As one would expect, the share of income from wealth is much higher for the higher portions of the top quintile.

18. In the case of households with multiple adults, life expectancy is the maximum of life expectancies of the head of household and spouse. Information on remaining lifetimes is taken from the tables on vital statistics (U.S. Census Bureau 2002, Table 93).

19. The only exception to this procedure was educational assistance, for which we lacked information to split the NIPA amount between recipients residing in households and student-housing. Hence, no modification was made to the amount reported in the ASEC.

20. Years of education and household income are available in the ADS. We calculated time available for housework by deducting weekly hours of rest (assumed to be 56) and usual weekly hours of work from the total hours in a week. Although the latter variable is available in the ADS, we used the imputed amount from the time-use survey in the calculation to ensure that the weekly hours spent on all activities do not exceed the total hours in a week.

\section{REFERENCES}

Canberra Group. Expert Group on Household Income Statistics: Final Report and Recommendations. 2001, Ottawa.

DeNavas-Walt, C., Cleveland, R., and Webster, Jr., B.H. U.S. Census Bureau, Current Population Reports, Income in the United States. Washington, D. C.: U.S. Government Printing Office, 2003, 60-221.

Hicks, U.K. The Terminology of Tax Analysis. The Economic Journal, March 1946, 38-50.

Kuznets, S.S., Epstein, L., and Jenks, E.. National Income and Its Composition, 1919-1938. New York: National Bureau of Economic Research, 1941.

Lakin, C. The Effects of Taxes and Benefits on Household Income, 2000-01. Social Analysis and Reporting Division, Office for National Statistics, U. K. http://www.statistics.gov.uk/, 2002.

Landefeld, J.S., and McCulla, S.H. Accounting for Nonmarket Household Production within a National Accounts Framework. Review of Income and Wealth, September 2000, 289-307.

Lerman, R.I. How Do Income Sources Affect Income Inequality? in the Handbook on Income Inequality Measurement, edited by Jacques Silber. Boston: Kluwer Academic Publishers, 1999, 341-58. 
MeIntyre, R.S., Denk, R., Francis, N., Gardner, M., Gomaa, W., Hsu, F., and Sims, R. Who Pays? A Distributional Analysis of the Tax Systems in All 50 States (second edition). Washington, D.C.: Institute on Taxation and Economic Policy, 2003.

National Research Council. Beyond the Market: Designing Nonmarket Accounts for the United States. Panel to Study the Design of Nonmarket Accounts, edited by K.G. Abraham and C. Mackie. Washington, DC: The National Academies Press, 2005.

Organization for Economic Co-operation and Development. Household Production in OECD Countries: Data Sources and Measurement Methods. Paris: OECD, 1995.

Ruggles, P., and O'Higgins, M. The Distribution of Public Expenditure among Households in the United States. Review of Income and Wealth, June 1981, 137- 64.

Ryscavage, P.A. Surge in Growing Income Inequality? Monthly Labor Review, August 1995, 51-61.

Weisbrod, B.A., and Hansen, W.L. An Income-Net Worth Approach to Measuring Economic Welfare. The American Economic Review December 1968, 1315-29.

Wolff, E.N. and Zacharias, A. The Levy Institute Measure of Economic Well-Being. Indicators: The Journal of Social Health, Fall 2003, 44-73.

Wolff, E.N., Zacharias, A. and Caner, A. Levy Institute Measure of Economic Well-Being, Concept, Measurement and Findings: United States, 1989 and 2000. February. Annandale-on-Hudson, N.Y.: Levy Economics Institute of Bard College, 2004.

Yao, S. On the Decomposition of Gini Coefficients by Population Class and Income Source: A Spreadsheet Approach and Application. Applied Economics, October 1999, 1249-64.

Yeung, J.W., and Stafford, F.. Parental Child Care Time Allocation. Unpublished manuscript, April, 2003. 